\section{(6) OPEN ACCESS}

\title{
Ending versus controlling versus employing addiction in the tobacco-caused disease endgame: moral psychological perspectives
}

\author{
Lynn T Kozlowski
}

\begin{abstract}
Correspondence to
Dr Lynn T Kozlowski, Department of Community Health and Health Behavior, School of Public Health and Health Professions, University at Buffalo, State University of New York, Buffalo, NY 14214-3079, USA; lk22@buffalo.edu
\end{abstract}

Received 30 September 2012 Revised 23 January 2013 Accepted 24 January 2013
To cite: Kozlowski LT. Tob Control 2013;22:i31-i32.

\begin{abstract}
Even though interest in reducing or eliminating tobaccocaused diseases is a common goal in tobacco control, many experts hold different views on addiction as a target of intervention. Some consider tobacco-caused addiction as a tobacco-caused disease to be eliminated alongside the other diseases. Some consider tobaccocaused addiction as a much lower priority disease to be eliminated, and a subset of this group is prepared to employ addiction to tobacco (nicotine) as a tool to reduce other tobacco-caused disease. These varying attitudes towards ending, controlling or employing tobacco addiction to reduce damage from tobacco use constitute quite different approaches to tobacco control and cause conflict among those in tobacco control. Moral psychological analyses argue that there is more than scientific evidence involved in supporting this continuum of approaches. Divergent values also influence positions in tobacco control. Attention to these values as well as the scientific evidence should be included in policy and practice in tobacco control. It is not that one constellation of values is necessarily superior, but debates need to be informed by and engage discussions of these values as well as the scientific evidence.
\end{abstract}

Everyone interested in tobacco control for public health benefit strives to reduce and, if possible, eliminate tobacco-caused diseases. The field divides, however, into factions according to the views on the implications of addiction to tobacco-nicotine. 'Tobacco' or 'nicotine' addiction can represent overlapping concepts, but they can also refer to differing levels of harm reduction or addiction liability. The issues engaged here can arise with respect to either tobacco or nicotine addiction. Some consider tobacco-caused addiction as a tobacco-caused disease to be eliminated alongside the other diseases. ${ }^{1}$ Some consider tobacco-caused addiction as a much lower priority disease to be eliminated, ${ }^{1}$ and a subset of this group is prepared to consider addiction to tobacco (nicotine) as a tool to reduce other tobacco-caused disease. ${ }^{2}$ These varying views on ending, controlling or employing tobacco addiction can be a source of conflict between tobacco control advocates and researchers. Moral psychology ${ }^{3}$ may contribute to understanding the bases of some of the variations in positions on nicotine addiction and other issues in tobacco control.

Some define tobacco addiction as a disease, ${ }^{4}$ but not all definitions of addictions require that. ${ }^{5} 6$ Even if classed as a 'brain disease', sociopolitical and ethical implications of the classification complicate matters. ${ }^{78}$ Recent work on 'nicotine addiction phenotypes' shows that understanding of addiction is not yet very advanced. ${ }^{9}$ Whether 'disease' or not, addiction does not mean that addicts are unable to permanently stop using tobacco. Many tobacco addicts do stop using tobacco. Whether or not a 'disease', there remains the question of the relative importance of addiction per se as a priority for public health concern.

Tobacco control often deals with what ifs. If the world were changed in a particular way, then it is projected what would happen. If smokers switched from cigarettes to nicotine replacement therapy or smokeless tobacco, then they would reduce their risk of harm. Or if teenagers adopted smokeless tobacco products or e-cigarettes, then they would later switch to more dangerous cigarettes. Empirical research does inform positions on such matters, but there is also an influence of values as well as legal and economic issues.

One of the leading researchers of moral psychology describes five core principles or 'intuitions' about morality. ${ }^{3}$ The first two have long been well recognised as fundamental to morality: (i) 'harm, care, and altruism (people are vulnerable and often need protection)' and (ii) fairness, reciprocity and justice; the next three principles also need to be recognised as important but have often been ignored in discourse: (iii) loyalty to one's community, (iv) respect for authority and (v) appreciation of bodily and spiritual purity. For example, think of political parties that range from very conservative to very liberal. Research has shown that, while both groups do value altruism and fairness, these principles are relatively more important for the liberal. In contrast, the additional three values above are relatively more important as conservatism increases.

We recently applied a moral psychological analysis to expert and popular views of the use of smokeless tobacco for harm reduction. ${ }^{10}$ Those supporting harm reduction were found to be expressing anger at the violation of individual rights, and those opposing harm reduction were expressing disgust and concern that support of smokeless tobacco was violating public health norms, authority and inconsistent with values of bodily purity. The study of moral psychology has found that 'anger' and 'disgust' are linked to violations of different values. Of course, scientific evidence was also discussed in the disputes analysed, but especially when the science base is limited, there is an opportunity for values to have an influence on which findings and concerns are viewed as most important. 
The point of applying moral psychology is not to say one position is either more or less moral than another, but that different moral principles are weighted more heavily from one position than another. As one moves from the positions of eliminating tobacco addiction, to minimising addiction, to actively trying to employ addiction to reduce deadly tobaccocaused disease, there is increased emphasis on individual rights and protection of the smoker who is not prepared to quit tobacco use and at the same time decreased emphasis on the principles of bodily purity, respect for authority and concern for the group.

There are complex factors behind why some of us are 'hard' vs 'soft' on addiction as an issue. It is not just scientific evidence or training that informs these positions but also complex moral values influenced by moral psychology that are at play. The point of invoking themes from moral psychology is not to say one position is either more or less moral than another but to try to enrich the assessments of our varying positions and identify issues that can keep factions from agreeing. As the tobacco control community seeks an end to tobacco-produced disease, the means to the end will be the critical factor. Underlying those means are different philosophies and moral psychologies as well as lines of scientific evidence. Debates need to be informed by and engage discussions of these values as well as scientific evidence.

\section{Key messages}

- As the tobacco control community seeks an end to tobaccoproduced disease, the means to the end will be the critical factor.

- Underlying those means are different philosophies and moral psychologies as well as lines of scientific evidence.

- Debates need to be informed by and engage discussions of these values as well as scientific evidence.

\section{Competing interests None.}

Provenance and peer review Not commissioned; externally peer reviewed.

Open Access This is an Open Access article distributed in accordance with the Creative Commons Attribution Non Commercial (CC BY-NC 3.0) license, which permits others to distribute, remix, adapt, build upon this work non-commercially, and license their derivative works on different terms, provided the original work is properly cited and the use is non-commercial. See: http://creativecommons.org/ licenses/by-nc/3.0/

\section{REFERENCES}

1 Robins R. The seduction of harm reduction: Proceedings from the September 2004 Summit. Sacramento, CA: Department of Health Services; 2005:1-120. http://www. cdph.ca.gov/programs/tobacco/documents/ctcpharmreductproceedcompletebooklet. pdf (accessed 13 Dec 2013).

2 Gartner C, Hall W. The potential role of Snus in tobacco harm reduction. Addiction 2009;104:1586-7.

3 Haidt J. The new synthesis in moral psychology. Science 2007;316:998-1002.

4 Smith DE. The process addictions and the new ASAM definition of addiction. J Psychoactive Drugs 2012;44:1-4.

5 Fingarette H. Heavy drinking: the myth of alcoholism as a disease. Berkeley: University of California Press, 1988.

6 Kalant H, Clarke PBS, Corrigall WA, et al. The Royal Society of Canada/La Société royale du Canada. Tobacco, Nicotine, and Addiction: A Committee Report. Health and Protection Branch, Health and Welfare Canada; 1989.

7 Dingel MJ, Karkazis K, Koenig BA. Framing nicotine addiction as a 'disease of the brain': Social and ethical consequences. Soc Sci Q 2011;92:1363-88.

8 Hinshaw SP, Stier A. Stigma as related to mental disorders. Annu Rev Clin Psychol 2008;4:367-93.

9 Swan GE, Lessov-Schlaggar CN, Bierut LJ, et al. Status of genetic studies of nicotine dependence (Chapter 2). In: National Cancer Institute, Phenotypes and Endophenotypes: Foundations for Genetic Studies of Nicotine Use and Dependence, Tobacco Control Monograph No. 20. Bethesda, MD: U.S. Department of Health and Human Services, National Institutes of Health, National Cancer Institute. NIH Publication No. 09-6366, August 2009.

10 Alderman J, Dollar KM, Kozlowski LT. Understanding the origins of anger, contempt, and disgust in public health policy disputes: applying moral psychology to harm reduction debates. J Public Health Policy 2010;31:1-16. 